\title{
PRICE-MINIMISING BEHAVIOURS IN RESPONSE TO INCREASING TOBACCO PRICE: A CROSS-SECTIONAL STUDY OF STUDENTS
}

Background: The public health benefits of tobacco taxation are undermined when smokers engage in price-minimising behaviours other than quitting in response to rising prices. These include switching from smoking manufactured cigarettes to cheaper alternatives such as rollyour-own (RYO). Young adults are particularly sensitive to tobacco prices.

Methods: 314 students at the University of Nottingham, UK completed an online survey about their current smoking behaviour and their likely responses to hypothetical increases in the price of tobacco.

Results: Cessation intent was linked to price, as was the likelihood of switching to cheaper products. Although only $7 \%$ said they would quit in response to a $£ 0.50$ increase in the price of their product, $68 \%$ said they would quit if it doubled. Among manufactured cigarette smokers who would switch products if the price of cigarettes doubled, $33 \%$ said they would switch to RYO. $44 \%$ stated they would switch to e-cigarettes if combustible tobacco became unaffordable.

Conclusions: Large price increases could reduce prevalence among this age group, though this effect would be potentially be undermined by young adult smokers accessing cheaper alternatives to manufactured cigarettes. The apparent viability of e-cigarettes as a priceminimising substitute for smoking may be encouraging from a public health perspective. 


\section{PRICE-MINIMISING BEHAVIOURS IN RESPONSE TO INCREASING TOBACCO PRICE: A CROSS-SECTIONAL STUDY OF STUDENTS}

\section{Introduction}

The serious public health consequences of tobacco use are well documented. In high income countries approximately half of all long-term regular smokers will be killed by tobacco use (1) and in England, smoking remains the primary cause of preventable morbidity and premature mortality (2). People usually start smoking as teenagers (3) and tend to become habitual smokers as young adults (4). From a public health perspective, tobacco control interventions which can effectively reduce both smoking initiation and escalation among young adults are therefore crucial for reducing long-run smoking prevalence at the population level (4).

Price is a key determinant of smoking initiation and of progression through the stages of uptake towards habitual smoking (4-6). Since raising the price of tobacco products reduces demand for tobacco in all age-groups (5-7) but particularly among young adults $(4-6,8,9)$, it follows that smoking prevalence in this age group would be much reduced by tax policies which diminish the affordability of tobacco. Young people may offset the effects of price increases by engaging in price-minimising strategies $(10,11)$ including smoking-related behaviours, such as quitting or reducing consumption; and product-related changes involving switching to a cheaper brand in the same product category (10), to an alternative form of tobacco such as roll-your-own (RYO), to illicit tobacco, or as a relatively recent new option, to tobacco-free forms of nicotine delivery such as electronic cigarettes. Whilst substantial health benefits accrue from quitting or else switching to electronic cigarettes, other priceminimising behaviours undermine the public health benefits of tobacco taxation. A number of studies from Europe, the USA and Australia have demonstrated that smokers engage in price 
minimising behaviours other than quitting in response to price increases, including switching to cheaper brands and RYO, cutting down, and making multipack purchases.(11-15). Studies also indicate that quitting behaviour increases as the magnitude of price rises increases.(12, 14) However, most of these studies have focussed on adult smokers, and none have been conducted in the UK. Furthermore, the majority of studies were conducted prior to the recent surge in the popularity of electronic cigarettes.

Since price-minimisation among young smokers in the UK has to date received relatively little research attention, this exploratory study was carried out to investigate young adults' sensitivity to tobacco prices and their likelihood of engaging in price-minimising behaviours, and how the price of factory-made cigarettes may influence demand for different tobacco products, illicit tobacco and electronic cigarettes among young adult smokers.

\section{Methods}

\section{Data collection}

Data were collected using an online survey of students aged 18 or over enrolled at University of Nottingham (UoN) for the 2013-14 academic year, and who reported that they had smoked at least one cigarette in the past 12 months. Students were mainly recruited by cluster sampling of University departments. Our cluster sample was drawn by randomly selecting three of the five university faculties, three schools within each faculty, and then all students enrolled on two courses in each school. These students were either emailed an invitation to take part or a message was posted on a relevant forum within the UoN virtual learning environment. Where consent was not gained from the course administrator to contact students, replacement courses were selected from the original randomisation list. We had not previously recruited survey participants in this way, and were therefore unsure whether this would be an effective recruitment method. In order to maximise our sample size, students 
were also recruited via opportunistic recruitment through advertising and word-of-mouth. Opportunistic recruitment involved advertising on the UoN intranet portal and on digital screens around the Students' Union building. Study invitations were also posted on several UoN-affiliated pages on Facebook. Participation in the study was incentivised with each respondent offered the opportunity to be entered into a prize draw to win a $£ 50$ shopping voucher.

Respondents were invited to complete a questionnaire including questions on demographic characteristics, current smoking behaviour, e-cigarette use and illicit tobacco purchases; and then asking participants what they would do if the price of their current tobacco product increased today by the following amounts: $£ 0.50, £ 1, £ 2.50, £ 5$ or a doubling in price. These questions were based on those used in a similar study by Ross et al.(16) For each hypothetical price increase, respondents were asked whether they would consider engaging in any of the following price-minimising behaviours: quitting; reducing consumption; downtrading to a cheaper brand; or switching to a cheaper alternative product, such as from cigarettes to RYO tobacco. For each hypothetical price increase, respondents were also asked whether they would consider switching to using a different tobacco/nicotine product altogether. For all respondents answering 'yes', a supplementary question asked participants which product they would be most likely to switch to. A further question asked whether participants had ever previously changed the product they smoked because the price had increased. Finally, participants were asked whether they would consider using an electronic cigarette or buying illicit tobacco if legal tobacco products became too expensive.

Wherever possible, we used or adapted questions that have already been used in published studies. Our questionnaire was piloted among a small sample of smokers and edited before it was distributed to students. The survey questions are listed in full in the online appendix to 
this paper. The questionnaire was hosted on the Bristol Online Surveys (BOS) website and was open for a period of 28 days from $14^{\text {th }}$ May 2014 until $11^{\text {th }}$ June 2014.

\section{Statistical analysis}

Survey data were extracted from the Bristol Online Surveys server and imported into Microsoft Excel before analysis in STATA Version 11.0. In addition to basic descriptive statistics we used univariate logistic regression to explore the effect of smoking frequency on potential price-minimising behaviours, and to compare the responses of those who ever purchase their own tobacco with those who never purchase tobacco. In these analyses, smoking frequency was categorised as a binary variable with 'regular smoker' including all those who indicated that they smoke daily/on most days/weekly; and 'infrequent smoker' including those who smoke socially/occasionally/rarely. The variable 'quantity purchased' was categorised into a binary exposure with respondents either coded as 'ever purchasers' and 'never purchasers'. Multivariate models were then built by adding potential confounders (ethnicity, income, type of tobacco smoked, smoking frequency, quantity smoked (at weekends and on weekdays), age when first started smoking and tobacco dependence) one by one to the model to determine whether they significantly affected the association between smoking frequency and each outcome. Any variable which altered the univariate odds ratio by more than $10 \%$ was included in the final multivariate model. Age and sex were included in the final logistic regression model as a priori confounders. It was estimated a priori that 100 participants were needed to estimate the proportion of students who would consider giving up smoking if the price of their current tobacco product increased by $£ 0.50$ to within $3.8 \%$ using $95 \%$ confidence intervals. 


\section{Ethics approval}

Ethics approval for the study was granted by the Ethics Committee of the Division of Epidemiology and Public Health at the University of Nottingham. 


\section{Results}

A total of 314 students completed the survey, including $220(70 \%)$ recruited by cluster sampling method and 94 (30\%) who responded to advertising. The 220 cluster sample respondents were drawn from an estimated total number of eligible students of 4768 , and on an assumption that $28 \%$ of these were current smokers (17), represent approximately $16.5 \%$ of the sample population, drawn from a target population of all 33,369 UoN students.(18)

Participant demographics are summarised in Table 1. The majority of respondents were female (63\%), white British (78\%), and aged under 24 (82\%). Disposable income (income left after basic living expenses) was less than $£ 500$ per month in $97 \%$ of respondents, and typically between $£ 100$ and $£ 249$ per month (49\%).

\section{TABLE 1}

\section{Current smoking behaviour and expenditure on tobacco}

Just over half of respondents (52\%) reported that they smoke manufactured cigarettes, $22 \%$ RYO tobacco, and $25 \%$ both (Table 1). Almost $25 \%$ of respondents stated that they had ever purchased illicit tobacco, with a further $12 \%$ indicating that they were unsure whether they had. Around half of participants (49\%) had ever tried an e-cigarette, and only 4 participants ( $1.27 \%$ of the full sample, $2.58 \%$ of e-cigarette ever users ) used an e-cigarette daily. A third of respondents reported that they smoked daily or on most days, one in 10 at least once a week, a third only occasionally/socially, while a quarter stated that they smoke only rarely (Table 1). 
One fifth of respondents never purchased their own cigarettes or tobacco. A quarter bought packs of 10 manufactured cigarettes, and a quarter bought packs of 20. Of those who bought RYO tobacco, $16 \%$ usually bought $12.5 \mathrm{~g}$ packs, $8 \% 25 \mathrm{~g}$ packs, and $2.5 \% 50 \mathrm{~g}$ packs. Of students who said they bought 10 packs of cigarettes most (79\%) usually paid $£ 2.50-4.99$, with $18 \%$ paying $£ 5-7.49$ and only 2 respondents paying less than $£ 2.50$. Of those usually buying packs of twenty, most paid $£ 5-7.49(42 \%)$ or $£ 7.50-£ 8.50(35 \%)$. There was a clear differential between the price paid by manufactured cigarette purchasers and RYO purchasers: $86 \%$ of those who usually bought $12.5 \mathrm{~g}$ packs of loose tobacco (equivalent to approximately 25 cigarettes (19)) paid £2.50-4.99.

\section{The potential impact of tobacco prices on smoking behaviour}

Participants' reported likely responses to increasing tobacco prices are presented in Table 2a. An increasing proportion of respondents indicated that they would give up smoking with each hypothetical rise in the price of their cigarettes or RYO tobacco; approximately $7 \%$ of participants indicated that they would quit in response to a $£ 0.50$ increase in tobacco prices, whereas almost $70 \%$ said that they would give up if the price of their current tobacco product doubled.

The proportion of respondents indicating that they would switch to an alternative tobacco or nicotine product also increased with each hypothetical rise in the price of their current tobacco product. Approximately $28 \%$ of those surveyed stated that they would switch to an alternative product following a $£ 0.50$ increase in the price of their existing product but this rose to over half in relation to a $£ 5$ increase or a doubling in price. Participants appeared more likely to engage in price-minimising behaviours other than quitting or switching products in response to smaller price increases. In response to a $£ 0.50$ price increase, approximately $35 \%$ said they would downtrade to a cheaper brand, approximately $31 \%$ said they would cut down 
on the amount they smoked and approximately $25 \%$ said they would supplement their existing cigarettes with a cheaper product. However, respondents were far more likely to say they would quit or switch to an alternative product rather than downtrade, reduce consumption or supplement with a cheaper alternative when the price of their cigarettes or tobacco increased by $£ 5$ or doubled. A third of respondents indicated that they had previously changed the product they smoked in response to increasing prices (data not shown).

Participants who said that they would consider switching to an alternative product in response to future price increases were asked a supplementary question about which product they would switch to. At least a third of smokers of manufactured cigarettes were most likely to switch to RYO tobacco. Approximately $25 \%$ of those who said they would switch products indicated that they would change to smoking illicit tobacco in response to price increases of $£ 0.50, £ 1$ and $£ 2.50$; this rose to $33 \%$ following a $£ 5$ increase and $39 \%$ for a doubling in price. Very few smokers of manufactured cigarettes indicated that they would switch to products such as e-cigarettes, water pipes or chewing tobacco/oral snuff in response to rises in the price of manufactured cigarettes.

Like manufactured cigarette smokers, a substantial proportion of RYO tobacco smokers indicated that they would switch to smoking illicit tobacco in response to price increases. Approximately $28 \%$ said that they would switch to illicit tobacco following a $£ 0.50$ increase in the price of licit tobacco, rising to $38 \%$ following a $£ 5$ increase. A higher proportion of RYO tobacco smokers stated they would switch to e-cigarettes compared with manufactured cigarette smokers. Very few RYO users indicated that they would switch to using water pipes or chewing tobacco/oral snuff if their current tobacco increased in price. 
A high proportion of dual users indicated that they would switch to RYO tobacco following price increases $-68 \%$ in response to a $£ 0.50$ increase, and $43 \%$ in response to a doubling in price.

TABLE 2

\section{Switching to electronic cigarettes and illicit tobacco in response to price increases}

$44 \%$ of all respondents indicated that they would consider using an e-cigarette, or using one more often, if tobacco became too expensive. (Table 3) Over a quarter (28\%) stated that they would be more likely to purchase illicit tobacco, or purchase it more often, if legal tobacco became too expensive.

\section{TABLE 3}

\section{Logistic regression analyses}

Univariate analyses suggested that regular smokers were less likely to say they would quit in response to price increases than those who smoke rarely. Conversely, frequent smokers were more likely to indicate that they would switch to smoking an alternative product than infrequent smokers, although many of the differences observed did not achieve statistical significance. Univariate analyses also suggested that respondents who purchase tobacco were more likely to say they would switch to smoking an alternative product than those who never purchase their own cigarettes (Table 4). In the multivariate models there were no statistically significant differences in price minimising behaviours between frequent and infrequent 
smokers, and only one between those ever purchasing tobacco and those never purchasing tobacco, which is likely to have occurred due to chance.

\section{TABLE 4}

\section{Discussion}

\section{Summary of findings}

This study suggests that among young adult smokers, tobacco prices need to rise substantially to be likely to generate significant reductions in smoking prevalence, and that the effect of price rises is likely to be seriously undermined by the availability of lower price options such as cheaper cigarette brands, RYO tobacco or illicit tobacco. Regular e-cigarette use in this population was low, but the use of e-cigarettes was considered as a potential priceminimising strategy by a substantial number of participants, particularly those who had already adopted RYO.

\section{Strengths and limitations}

Our study is limited to the opinions of a relatively small sample of students who, despite low current income, are more likely to come from relatively affluent families from the UK or overseas, and therefore may not be representative of the general population of adults of their age. We are unable to estimate our participation rate with accuracy but we know that at around $17 \%$ it is low, and again may not therefore be representative. University of Nottingham student statistics from 2013/14 indicate that female students are overrepresented in our sample; however our study nevertheless provides a valuable insight into the views and behaviours of an under-researched population.(20) 
Our findings are based on hypothetical price increases; they should be interpreted with caution, as responses to hypothetical pricing scenarios do not necessarily predict actual behaviour in response to real price rises. Nevertheless, they give some sense of the likely effectiveness of price rises in this context. Studies which have explored price minimising behaviours in response to real life price increases have demonstrated that they do occur, and that their impact may be substantial.(11-13) A German study found that prior to price increases, $11-16 \%$ of smokers intended to switch to cheaper tobacco products; following price increases, $11-20 \%$ actually switched. While a smaller proportion quit smoking in response to the increases, the study indicates that intended behaviour is often borne out in practice.(12) Furthermore, our study is able to shed light on students' willingness to switch to e-cigarettes, which is an area of research which has received little attention to date. There is a suggestion that some of our questions may not have been fully understood, as some participants reported that they would switch category to a product in the same category as the one they currently consumed. However these responses may have been meant to say that the respondent would not in fact change behaviour in response to the given price change.

\section{Discussion of study findings}

Our finding that approximately half of respondents indicated that they currently smoke factory-made cigarettes, while around a quarter of respondents reported dual use of both manufactured cigarettes and RYO tobacco is consistent with recent data estimating the prevalence of RYO use among British 16-24 year olds.(21) Dual use may itself represent a price-minimising strategy whereby respondents are supplementing their factory-made cigarettes with comparatively cheaper RYO tobacco. Future research could address young smokers' reasons for dual use. 
Clear price differentials between factory-made cigarettes and RYO tobacco were discernible from the data collected. This finding is consistent with the published literature which demonstrates that in the UK, as in many other jurisdictions, RYO tobacco retails for a significantly lower price than factory-made cigarettes as a consequence of asymmetries in excise duty across different tobacco products. $(21,22)$ This finding is particularly noteworthy in light of our findings that there is likely to be strong relation between the price of factoryproduced cigarettes and demand for RYO tobacco (i.e. positive cross-price elasticity) in this population. This re-emphasises the need to harmonise tax policies across tobacco products, in order to eliminate price differentials which encourage smokers to switch to alternative products rather than quitting in response to price increases.

The study found a clear association between the price of tobacco and smokers' intentions to quit, with an increasing proportion of respondents indicating that they would give up with each hypothetical rise in the price of their cigarettes or RYO tobacco. In addition, a large proportion of respondents reported that they would switch to a cheaper brand in response to an increase in the price of their tobacco product. Substantial price segmentation within the tobacco market means that even in the event of a price increase - which in practice have tended to take place predominantly among more expensive brands, leaving low-price products unchanged - cheaper brands would be available for most smokers.(23)

Our findings are in line with existing evidence that young smokers are likely to engage in price-minimising behaviours. For example, an Australian survey identified that younger smokers were more likely than older smokers to make both smoking-related and productrelated changes in response to tobacco tax increases (10). A Turkish study also found evidence that younger smokers were more likely to engage in compensatory behaviours in response to rising cigarette prices such as switching to cheaper brands and buying their cigarettes in bulk (13). Most existing studies have focussed on adult smokers; however, there 
are parallels between their findings and ours. Dunlop et al. found that in Australia, a substantial proportion of adult smokers tried to quit, cut down, or switched to cheaper brands or HRT after a price increase.(24) In a German study 4-8\% quit smoking in response to a price increase, $12-17 \%$ reduced consumption and $11-20 \%$ switched to cheaper products. Taken together, the existing evidence suggests that price minimising behaviours can occur across countries and in all age groups.

Few studies have explored the differential impact of price increases of varying magnitudes. Only $7 \%$ of respondents in our study indicated they would give up if the price of their current cigarettes increased today by $£ 0.50$; by contrast $64 \%$ said they would quit if the price increased by $£ 5$. Given that the duty on factory-produced cigarettes typically rises by around $£ 0.24$ annually,(25) our findings suggest that small incremental increases are not likely to induce large reductions in smoking prevalence among people from this population. This theory bears parallels with arguments put forward in the literature which stress that smokers' responses to tobacco price increases are closely related to the magnitude of the increase.(12, 16, 26) An Australian study found that larger hypothetical price rises motivated more smokers to consider making a quit attempt.(24) While this study adds strength to the arguments that large magnitude price increases could have substantial impacts on prevalence on young adults, the predicted cessation rates are hypothetical and thus may not be borne out in reality. Nevertheless, policymakers should consider the magnitude of tax increases when determining excise tax levels for tobacco products.

Our results suggest that illicit tobacco is likely to act as a substitute for licit tobacco. Although there is evidence from the international literature suggesting that young adults are relatively more likely to buy illicit tobacco than other age groups, we are not aware of any current evidence in the UK literature which demonstrates that a substantial proportion of smokers from this population would switch to using illicit tobacco as a means of offsetting 
increases in the rise of duty-paid tobacco. This finding has implications for both public health and government taxation revenues. Stringent efforts against illicit trade will need to be maintained if the public health impact of taxation is to be optimised.

Findings from this study also indicate that e-cigarettes are a viable substitute to combustible tobacco for some young adult smokers faced with increasing tobacco prices. This may be encouraging from a public health perspective given the likely reduced harm posed by these tobacco-free devices. $(27,28)$ However, it should be noted that when presented with a choice of substitutes for cigarettes, more respondents indicated they would switch to RYO tobacco or illicit tobacco rather than e-cigarettes. More research is required into the feasibility of promoting electronic cigarettes as a price-minimising alternative to combustible tobacco such that young adults may be inclined to use these devices in favour of more pernicious substitutes.

\section{Conclusions}

Whilst our study is based on hypothetical pricing scenarios, it highlights key issues in relation to price minimisation and the size of tobacco price increases which should be investigated in future research. Overall, this study suggests that the public health impact of tobacco taxation policies may be undermined as a result of young adult smokers engaging in price-minimising behaviours other than quitting in response to rising tobacco prices. Both illicit tobacco and electronic cigarettes may serve as substitutes for licit and/or combustible tobacco respectively. Large magnitude price increases across all tobacco products are required to induce significant changes in smoking prevalence among this population, and, in particular, measures are still needed to reduce price differentials between factory-made cigarettes and loose tobacco. More research is required into the viability of promoting e-cigarettes as a specific price-minimising strategy for young adults. 


\section{References}

1. Jha P, Chaloupka FJ. The economics of global tobacco control. BMJ. $2000 ; 321(7257): 358-61$.

2. Department of Health. Healthy Lives, Healthy People: A Tobacco Control Plan for England In: Health. Do, editor. 2011.

3. Health and Social Care Information Centre. Statistics on Smoking: England, 2013. 2013.

4. International Agency for Research on Cancer. Effectiveness of tax and price policies for tobacco control: IARC handbook of cancer prevention, vol. 14. Lyon, France: IARC; 2011.

5. Jha P, Peto R. Global Effects of Smoking, of Quitting, and of Taxing Tobacco. New England Journal of Medicine. 2014;370(1):60-8.

6. Chaloupka FJ, Yurekli A, Fong GT. Tobacco taxes as a tobacco control strategy. Tobacco Control. 2012;21(2):172-80.

7. World Health Organization. WHO Framework Convention on Tobacco Control. Geneva2003.

8. Nikaj S, Chaloupka FJ. The Effect of Prices on Cigarette Use Among Youths in the Global Youth Tobacco Survey. Nicotine Tob Res. 2013.

9. Licht AS, Hyland AJ, O'Connor RJ, Chaloupka FJ, Borland R, Fong GT, et al. How Do Price Minimizing Behaviors Impact Smoking Cessation? Findings from the International Tobacco Control (ITC) Four Country Survey. International Journal of Environmental Research and Public Health. 2011;8(5):1671-91.

10. Dunlop SM, Perez D, Cotter T. Australian smokers' and recent quitters' responses to the increasing price of cigarettes in the context of a tobacco tax increase. Addiction. $2011 ; 106(9): 1687-95$.

11. Xu X, Pesko MF, Tynan MA, Gerzoff RB, Malarcher AM, Pechacek TF. Cigarette Price-Minimization Strategies by U.S. Smokers. Am J Prev Med. 2013;44(5):472-6.

12. Hanewinkel $R$, Isensee $B$. Five in a row - Reactions of smokers to tobacco tax increases: Population-based cross-sectional studies in Germany 2001-2006: Tobacco Control. 16 (1) (pp 34-37), 2007. Date of Publication: February 2007.; 2007.

13. Kostova D, Andes L, Erguder T, Yurekli A, Keskinkilic B, Polat S, et al. Cigarette prices and smoking prevalence after a tobacco tax increase--Turkey, 2008 and 2012. MMWR - Morbidity \& Mortality Weekly Report. 2014;63(21):457-61.

14. Guillaumier A, Bonevski B, Paul C, D'Este C, Doran C, Siahpush M. Paying the price: A cross-sectional survey of Australian socioeconomically disadvantaged smokers' responses to hypothetical cigarette price rises. Drug and Alcohol Review. 2014;2013(2):177-85.

15. Cornelius M, Driezen P, Hyland A, Fong G, Chaloupka F, Cummings K. Trends in cigarette pricing and purchasing patterns in a sample of US smokers: findings from the ITC US Surveys (2002-2011). Tobacco Control. 2015;24(Suppl 3):iii4-iii10.

16. Ross H, Powell LM, Tauras JA, Chaloupka FJ. New evidence on youth smoking behavior based on experimental price increases. Contemporary Economic Policy. $2005 ; 23(2): 195-210$.

17. Health and Social Care Information Centre. Statistics on Smoking: England, 2013. 2013. Available from http://www.hscic.gov.uk/catalogue/PUB11454 Accessed April 27th 2015.

18. University of Nottingham. Student population 2013/14. Available from https://www.nottingham.ac.uk/about/facts/studentpopulation20132014.aspx. Accessed 27th April 2015.

19. Darrall K, Figgins J. Roll-your-own smoke yields: theoretical and practical aspects. Tobacco Control. 1998;7:168-75.

20. University of Nottingham. Student Statistics 2013-14. Available from https://www.nottingham.ac.uk/spp/student-statistics/student-statistics-2013-14.aspx [Accessed 07/10/16] [ 
21. Gilmore A, Tavakoly B, Hiscock R, Taylor G. Smoking patterns in Great Britain: the rise of cheap cigarette brands and roll your own (RYO) tobacco. Journal of Public Health. 2015;37(1):78-88.

22. Young $D$, Yong $H-H$, Borland $R$, Shahab L, Hammond D, Cummings $M$, et al. Trends in Roll-Your-Own Smoking: Findings from the ITC Four-Country Survey (20022008). Journal of Environmental and Public Health. 2012;2012.

23. Gilmore A, Tavakoly B, Taylor $\mathrm{G}$, Reed $\mathrm{H}$. Understanding tobacco industry pricing strategy and whether it undermines tobacco tax policy: the example of the UK cigarette market. Addiction. 2013;108(7):1317-26.

24. Dunlop SM, Perez D, Cotter T. Australian smokers' and recent quitters' responses to the increasing price of cigarettes in the context of a tobacco tax increase. Addiction. $2011 ; 106(9): 1687-95$.

25. HMRC. Tobacco products duty. 2014; Available from http://www.hmrc.gov.uk/rates/tobacco-duty.htm.

26. Uppal N, Shahab L, Britton J, Ratschen E. The forgotten smoker: a qualitative study of attitudes towards smoking, quitting, and tobacco control policies among continuing smokers. BMC Public Health. 2013;13(432).

27. McNeill A, Brose L, Calder R, Hitchman S, Hajek P, McRobbie H. E-cigarettes: an evidence update. A report commissioned by Public Health England. 2015.

28. Royal College of Physicians. Nicotine without smoke: Tobacco Harm Reduction. London: RCP; 2016. 